\title{
The University of Technology Versus The Traditional Universities. Is the Gap Being Closed?
}

\author{
Talwanga Matiki
}

\section{Doi:10.5901/mjss.2014.v5n23p2126}

\begin{abstract}
In 2003 six new Universities came into existence in South Africa. Their existence has to be justified by the quality technological innovation they will foster in the socio-economic development of the country. These are the Universities of Technologies (UOTS). The UOTs are the new-generation knowledge Institutions. This conceptually put a demarcation between the UOTS and the traditional Universities (TUNIV), which can be defined as Science and theoretical Institutions of higher learning. Ten years after the inception of UOTs, Is the gap between the two types of Institutions widening or is the gap actually lessening. In order terms Is there any apparent sign which shows that the difference between these two types of institutions of higher learning is becoming clear. Can it be said that there is enough ground to justify the inception of the universities of technology?
\end{abstract}

Keywords: South African traditional university, university of technology

\section{Points of Convergence and Points of Divergence}

Looking at these two types of institutions of higher learning, we may acknowledge the existence of points of convergence, which are areas of learning both types of universities are offering to their students. There are also points of divergence, which should be the areas of demarcation. In the next paragraph we wish to show the actual points of convergence and of divergence.

The UOTs have each the faculty of Engineering, which most TUNIV do not have. So this is the point of divergence. Both types of universities have the faculty of Humanities. This is therefore the point of convergence. Walter Sisulu University (WSU) and Nelson Mandela Metropolitan University ( NMMU) are two of the TUNIV that have both engineering and other faculties. This is the result of the merging of Technikons and traditional type of University. In a sense these are no longer traditional universities rather modern types of university.

Comparing these two types of universities (UOT and TUNIV ) would only be fair if we consider the areas of divergence. The comparison should be done in the area of fields that they both do, with the emphasis of checking the way they do it. On one hand we should be able to sense a flair of technological approach compared to the theoretical aspect which characterize the traditional universities.

With technology ever changing, the challenge of the UOT is to design curriculum which must match to the standard of the industry concerned. The UOT must train students in a way such they become relevant at the work place. For this purpose the UOT must have a constant check at the changes taking place at the industry. If possible they may even suggest the trend or the way the future generation will be shaped. The Work Integrated Learning ( WIL) provides a monitoring tool for that purpose. WIL officers, in conjunction with university program heads will have to check the industry demands and device a proper way to address those issues.

We have taken into consideration the output of 2 institutions one for each type for the last 5 years, taking a closer look at the number of the higher degree awarded. We have checked the number of Doctorate degree awarded as well as the master degree. The two universities considered are Central University of Technology and University of Fort Hare. Our choice for these two was guided by the availability of information and the assumption these two are valid representatives of their categories.

We have considered only the number of degree awarded and have set aside the type of research topics and methods used to get to the results for two reasons. First this activity will require expertise which we do not have. Secondly we might not be able to change what has been achieved in the past. We can only make recommendations for future course of actions. The UOT must have this in mind. They are not TUNIV and a demarcation should always be apparent as to justify their existence.

There is no doubt an almost equal number of higher degrees have been awarded. Central University of Technology (CUT) has the most doctorates in academics staff of all the Universities of technology in South Africa. Considering the relative stage of infancy of this UOT (4), we are able to say the momentum is great enough for launching 
into orbit where clear cut distinction between the two types of institutions will be exposed.

A tree is known by the quality of the fruit it produces. From the kind of research undertaken by the students and researchers alike, it will be possible to tell whether or not the focus is on track.

As said earlier our focus is mainly tracing the way the UOT shall do the things in the area of convergence differently from the usual and traditional TUNIV's approach. In the next paragraph we wish to elaborate on what could be the teacher education approach of the UOT to meet the need of secondary schools around the country.

\section{The UOT Teacher Education Approach}

\subsection{Production of pedagogical materials needed for the dissemination of CAPS}

CAPS is the Curriculum Assessment Policy Statement in vigour in South Africa. The OUT should have realized that most the Department of Basic Education ( DBE) workshops throughout the country are content based (3). Yet we know the equally importance of didactics. The UOT must undertake to organize didactics workshops for teachers of the district the UOT is located. Help develop packages for learners and for teachers.

Issues of policy, governance or of conflict resolution, though they are not of technological nature should still be considered in research. But this time they should be done with the technical innovation flair in mind. Our schools need more specialists in the content and pedagogical skills coupled with computer literacy.

Research in UOT should be questioning more science and less people's opinion. For example, when studying the quality of water in an area. The usual way is sending questionnaire asking How good, bad, excellent is the water in our town. The innovative way would be to take samples of water in different locations, at different times of a month or of year. A laboratory analysis may reveal how good or bad water is. What are the elements that have contaminated water? How can the municipality solve the issue and at what costs? Compare the costs of both buying treated water from shop, buying filter equipment and indeed compare this with the municipality bill. In a town such as Welkom, residents not only must pay water bill from the municipality, but still have to buy treated water fro shop. How much would the combined water bills compare to a single bill one should the municipality treat water and service residents with a clean metal- free water.

\section{Pioneering the Emergence of Techniques of Communication in Education}

The new techniques of communication have captured the world with its unprecedented combination of texts, image and sound. Considering the immense progress made in this regards, it become imperative that the education system should consider aligning the future of teaching-learning processes accordingly. More and more students have paid work and family commitments, yet they also value the support offered by a campus-based experience. Students want more flexible ways to learn. To increase flexible access to "learning on the go", they will be able to learn using more online and webstreamed material while at the same time enjoying flipping to the traditional face-to-face learning (1).

Without actually ignoring the existing progress and experiences made in education, researchers should device federally a plan to foster the new technologies in dissemination and diffusion of educative multi media. This will help to blend the world of written text and that of seen image. With its supporting tools of audio-visual, image and text, the computer has the potential to stimulate creativity on the side of learners and adults alike.

When logged on a network (local or internet), learners can learn in groups; working beyond the usual confinement of a class-room; having access to many experts in the domain of the study; afford having a teacher permanently at his/her disposal.

Though it seems hard to harmonize the existing model of classroom and the avenues that are offered by the new technologies industries, the UOT have no choice than pioneering the implementation of future class-room project. In a way the UOT have to reinvent the university. In this regard we are aware that with this technologies will emerge new forms of exercising learner's rights. We also expect that the Other foreseen challenges would be the methods of conducting a physics or a chemistry lesson. We have in mind the practical aspect of these subjects. In what way an experiment in chemistry might be conducted in the actual absence of the instructor?

In our opinion, the new project should start with first the implementation of the micro-lesson as recommended by Mavula and Tal in (2). If one can master the skill of communication in class in its initial stage, then He/she may improve it to the level of communicating in a broader scale.

The e-learning project which the Central University of Technology has named E-Thuto is a step in the right direction. In the E-Thuto, lecturers can upload activities, which his/her students get access via their account. It is an 
effective mean of widening class activities and a way of lengthening contact time since students can access learning material even after hours.

At this stage communication between lecturers and students is a one-way traffic. Students are not enabled to respond to the instructor.

With regards to technological innovation the CUT has taken a step forward classroom technology with the Active Learning Centre $(A L C)$. This centre is a collaborative learning space with a plethora of technologies such as iPads, interactive white boards, audio-visual equipment and multiple display surfaces to aid and enhance the learning experience of students. This technological advancement will greatly enhance the instruction capabilities of lecturers, stimulate students active participation (1)

\section{A Useful Combination to be Exploited}

The UOTs have beside the usual faculties of management science, humanities which are also found in most TUNIV, the Engineering, information technology, health and environmental sciences faculties.

Clearly, the UOT have a vast field for development.

The faculty of engineering can add departments such as electronics, electro-mechanics, mechatronics, avionics, aviation, etc..

Imagine the immense possibilities that emerge when specialists in education, IT, computer science, electronics, mathematics, biomedical technology and others would come and share their knowledge together. This coming together would be profitable only if these experts have over-lapping interests. The UOT have fortunately all these people among their personnel. This is the kind of combination the UOT must exploit for their future endeavour. It would be of great interest to check how the universities which are a fruit of the technically-inclined Technikon and Universities of science have actually merged academically.

One example to emulate is the case of CUT which is taking a lead in innovations that will change the face of medical science in South Africa.

In a combined effort of their Centre for Rapid Prototyping and Manufacturing (CRPM), their Product Development Technology Station (PDTS), and the Faculty of Engineering and IT, including Dr van den Heever, an Extraordinary Professor at CUT, they have achieved a hard work and a meaningful contribution towards the successful completion of the two surgical operations on 23 July 2014. This team has changed the lives of two patients whose mandible implants were moulded with the use of 3-D printing. These operations made CUT a household name when millions of South Africans were glued to their televisions during a prime-time slot to witness this wonderful story. The team showed the world how this technology can restore the dignity of ordinary people who had lost parts of their faces due to cancer. This is the first of its kind in the country, and they make CUT stand proud at the forefront of innovation in this field! (5)

Another area of focus for the UOT is the area of innovation in entrepreneurship and community engagement programmes. The UOT must aim to become entrepreneurial universities.

\section{References}

Christo Hutler, Gratia Dec 2013

Vala Mavula and Matiki Talwanga, Perspectives of strengthening primary and high school teaching practices in South Africa, (Mediterranean journal of education social research, Mcser),Sept 2014 on print.

WA. Olivier, reflection on the training of teachers for the CAPS mathematics curriculum GratiaCUT, December 2013, p24

Acting Vice-Chancellor's Communiqué(31/7/14) hdejager@cut.ac.za 